\title{
INFLUENCIA DEL USO EXCESIVO DE LAS REDES SOCIALES EN EL RENDIMIENTO ACADÉMICO DE LOS ESTUDIANTES UNIVERSITARIOS.
}

\author{
Influence of the excessive use of social networks in the academic performance of university \\ students
}

\begin{abstract}
Héctor William Carlos Cruces ${ }^{1}$
${ }^{1}$ Docente de la Facultad de Ciencias Económicas y Negocios Internacionales de la Universidad Nacional San Luis Gonzaga de Ica
\end{abstract}

Sr. Editor

He leído el artículo científico titulado "Influencia del Uso excesivo de las redes sociales en el rendimiento académico de los estudiantes del III ciclo de la facultad de Medicina Humana de la Universidad Nacional San Luis Gonzaga de Ica 2017 I “ (1), es muy interesante y preocupante en esta era globalizada, estando de acuerdo con el autor respecto a la influencia excesiva de las redes sociales en el rendimiento académico dentro de los múltiples factores que influyen el rendimiento académico como los sociales, económico, psicológico, etc., se atribuye otro factor como la adicción a las redes sociales que ocasionan la pérdida de tiempo dejando de lado las obligaciones, descuidando los estudios y el desarrollo académico.

Asimismo el estudio de Echeburúa y de Corral (2010) señala que" las redes sociales pueden interferir en las actividades que una persona realiza en la vida cotidiana, especialmente los jóvenes en el ámbito educativo" (2).

En la actual era digital, es imposible hablar de educación, sin considerar la influencia que ejerce la tecnología especialmente las redes sociales, en el proceso de trasmisión de informaciones.

Las redes sociales cumplen hoy en día una labor de socialización importante, especialmente en los jóvenes estudiantes, los mismos que influye en la sociedad principalmente en la educación, trascendiendo en el rendimiento académico, considerando que la mayoría de los alumnos que ingresan a la vida universitaria, por no decir todos, forman parte de una red social, que les permite comunicarse con sus contactos, información , estados anímicos, fotos, música, videos, así como el establecimiento de grupos corporativos para transmitir temas específicos. Las redes sociales e internet llegaron para quedarse y establecerse en la sociedad, es difícil imaginarse hoy en día un mundo globalizado sin herramientas que le permita un rápido acceso a la información en tiempos más cortos y efectivos, que hace algunos años.

Lo importante de las redes sociales es saber cómo utilizarlos y sus resultados serán muy útiles en lo personal, empresarial, educación mejorando el rendimiento académico de los estudiantes dependiendo del uso que le demos a las diferentes redes sociales.

\section{Correspondencia:}

Dr. Héctor William Carlos Cruces

Correo electrónico:

arturogutierrezh.@hotmail.com

\section{REFERENCIAS BIBLIOGRÁFICAS}

1. Arroyo J. Influencia del usos de las redes sociales en el rendimiento académico de los estudiantes del III ciclo de la facultad de Medicina Humana de la Universidad Nacional San Luis Gonzaga de Ica 2017 I Rev. enfem. vanguard. 2018; 6(1): 18-24

2. Echeburúa E, De Corral. Adicción a las nuevas tecnologías y a las redes sociales en jóvenes: un nuevo reto. Rev. Adicciones Palma de Mallorca, España .2010; 22(2) : 91-95 ( Citado el 30 de Junio 2018) Disponible en: http:/ www.redalyc.org/articulo.oa?id=289122889 $\underline{001}$

Recibido: 26/10/2018 